\title{
The Situation of Violence in the High Schools of Shkodra City
}

\author{
Zamira Shabani ${ }^{1}$, Irena Shala ${ }^{1}$, Julian Kraja ${ }^{1}$, Vera Gjinaj ${ }^{1}$, Emiljano \\ Pjetri $^{1}$
}

\begin{abstract}
Background: Any behavior or attitude that harms the physical, emotional, and sexual well-being of one or more persons and affects the termination of the individual's normal development is considered as violence. Violence at school includes behaviors such as: victimization of a child and teachers, raping of a child and / or a teacher, physical and psychological harassment, cyber threatening, controversies, bullism, physical and psychological harm, teachers and students sexual violence, using of weapons in school environments. The main violence forms at school are: teachers to students, students to teachers, students to students.

This is a punctual, transversal, cross-sectional study. 100 students at high school of Shkodra city participated in this study. The sample selection was randomized. Students of 14-18 years old; 63 females and 37 males were included in the study. The timeframe of the study was January - February 2018. The information was gathered from face to face interviews using standatized questionnaires: Global School-based Student Health Survey (GSHS) 2003, Core-Expanded Questions for the Violence and Unintentional Injury Module Violence (adapted). The information collected by the questionnaires was confident, self-report and with permission of school. All data were calculated with Microsoft Office 2010.
\end{abstract}

Keywords: school, student, teacher, violence.

${ }^{*}$ Corresponding Author: Zamira Shabani

$\equiv \triangle$ Email: shabanizamira@yahoo.com

${ }^{1}$ University of Shkodra "Luigj Gurakuqi" Faculty of Natural Sciences, Department of Nursing, Shkoder Albania. 


\section{Full Text}

\section{Introduction}

Any behavior or attitude that harms the physical, emotional, and sexual wellbeing of one or more persons and affects the termination of the individual's normal development is considered as violence. Violence at school includes behavior such as: victimization of a child and teacher, raping of a child and / or a teacher, physical and psychological harassment, cyber threat, controversy, bullism, physical and psychological harm, teachers and students sexual violence, usage of weapons in school environments. The main forms of violence at school are: teachers to students, students to teachers, students to students.

Violence is a global problem around the world. The literature evidences that violence betwen students at school, causes negative efefects in accademic, physic, social, emotional and psicological aspects to the students. The ones that have experienced violence at school exhibit behavior such as anxiety, sadness, loneliness, insecurity, hyperactivity, impulsiveness, frustration, sorrow and anger. Lockwood (1997) states that about half of violence cases have occured at a school, gym or recreation center and the main reasons were: self-defense or resisting the antagonist's demands.

The more frequent victimization situations are verbal and exclusion, followed by verbal aggressions and violence against properties. The percentages of adolescents that suffer the extreme violence situations (like sexual abuse or being threatened by guns) are low, but the seriousness of these situations makes them very important. The aggressor role has a similar patron of results: The more frequent situations are verbal aggression and exclusion, violence against properties, and finally, extreme violence situations. (Pulido R., Martín Seoane G., Díaz Aguado, 2010)

The school authorities could be consistently effective in preventing and reducing the violence regarding schoolrelated factors. These factors like: teacher reprimands for racist comments made by students, anti-bullying policies, and formally communicated school rules are associated with decreased violence. The climate, culture, and structure of schools plays an important role in molding the level of violence that exists between students. Grunseit 2005.

Schools should gather students and discuss aspects of their own school environment important for the occurrence of violence at school. Even limited changes in the school environment can have positive results. The primary role of the school environment in violence prevention is stopping a violent event from its beginning or its extension. Focusing on the prevention of school violence is more effective than focusing on its punishment. (Nickerson AB, Martens $M P ., 2008$, Greene MB, 2005)

By bearing this in mind, we can say that positive relationships between students and feeling cared about by school personnel could help in the cessation of violent conflicts. It is also very 
important to create positive relationships with school security. Schools should work on improving relationships between students and school personnel as an effective violence prevention strategy. Overall the school environment should be considered as an important intervention point to reduce school violence. ( Lindstrom Johnson S. 2009, Greene $M B$, 2008).

\section{Material and methods}

This is a punctual, transversal, crosssectional study that includes 100 students at a high school of Shkodra City. The sample selection was randomized. Students of 14-18 years old; 63 females and 37 males were included in the study. The timeframe of the study was January - February 2018. The information was gathered from face to face interviews using standatized questionnaires: Global School-based Student Health Survey (GSHS) 2003, Core-Expanded Questions for the Violence and Unintentional Injury Module Violence (adapted). The information collected by the questionnaires was confident, selfreport and with permission of school. All data were calculated with Microsoft Office 2010.

\section{Results and discussion}

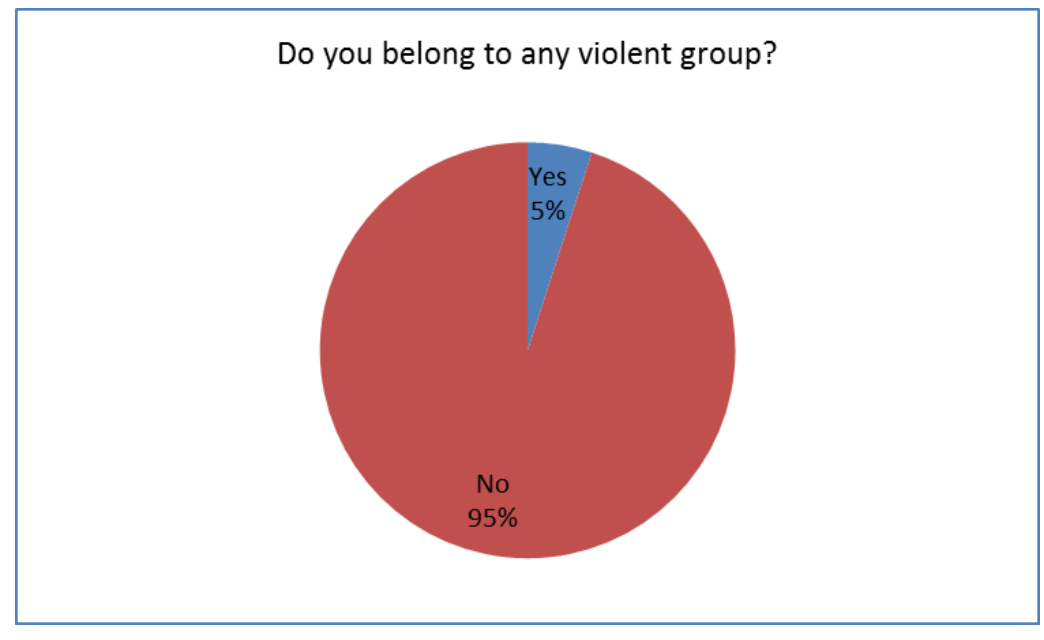

Figure 1: The presence of violent group

In this study we can observe that $5 \%$ of students belong in a violent group. The situation might be more problematic since the students do not refer alawys the true. We can evidence that $6 \%$ of them have been forced to have sexual intercourse. 


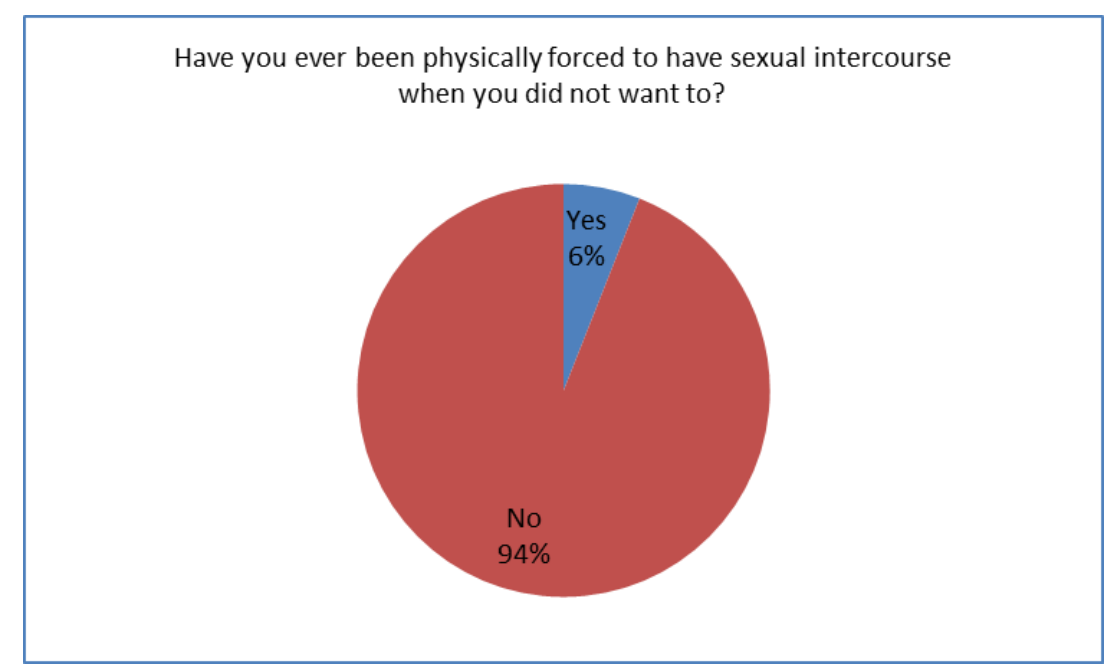

Figure 2: The presence of sexual intercourse forced

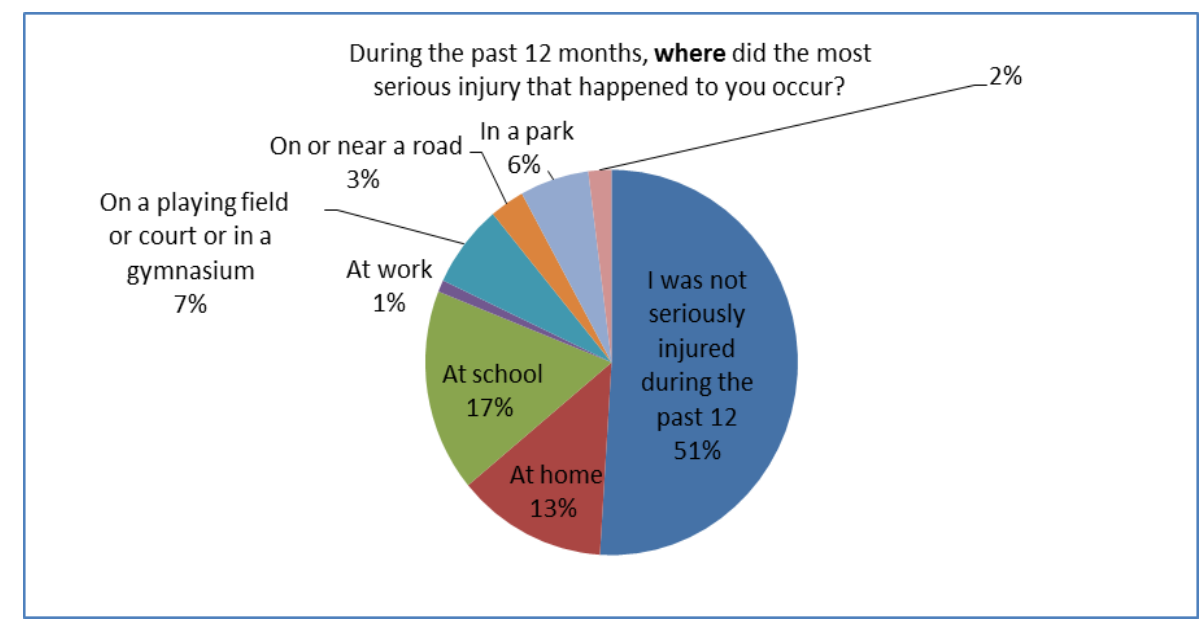

Figure 3: The place where the injuries occur

In the figure 3 we evidence that $17 \%$ of students refer that they have been violated at home and $13 \%$ at school. 


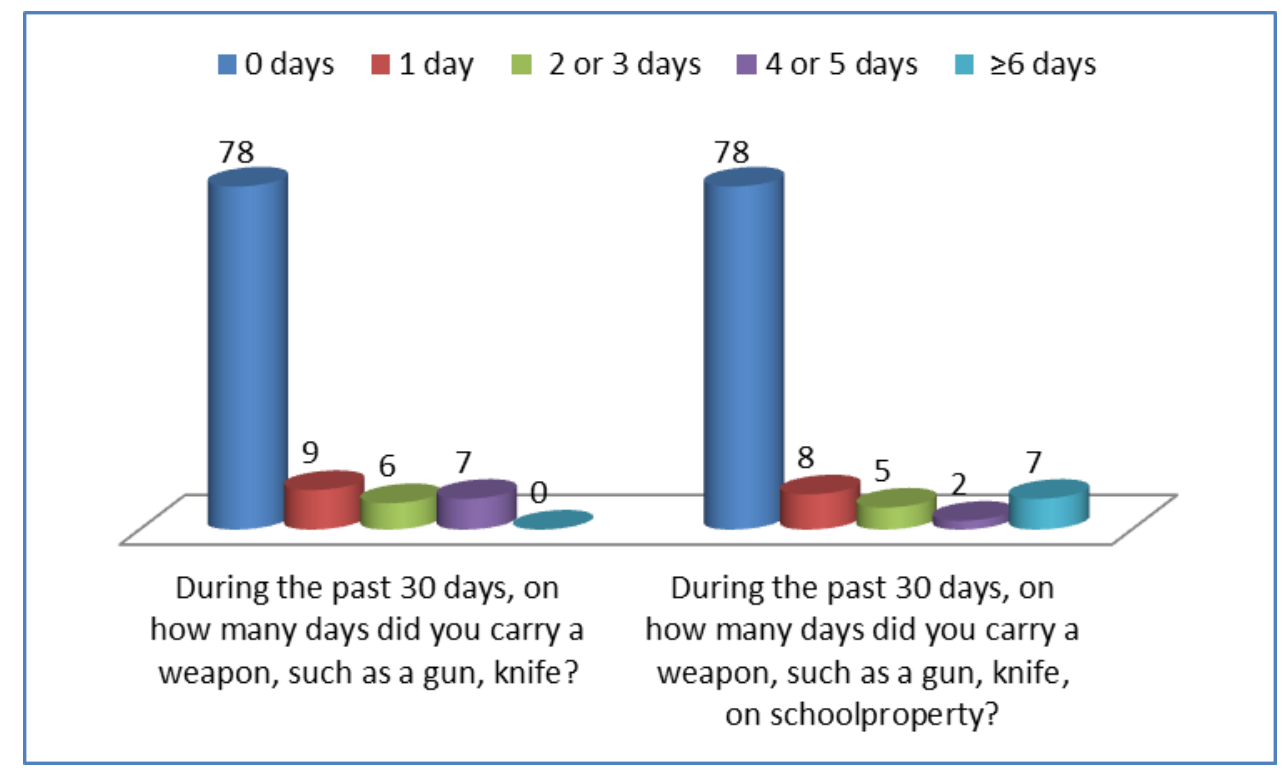

Figure 4: The answers about the keeping weapons

$78 \%$ of students don't carry gun or knife at school or outside its environment, but more than $8 \%$ of them refer that they have weapons while on school property or outside for at least one day during the past month. This situation is scary, because the probability to use them is not small.

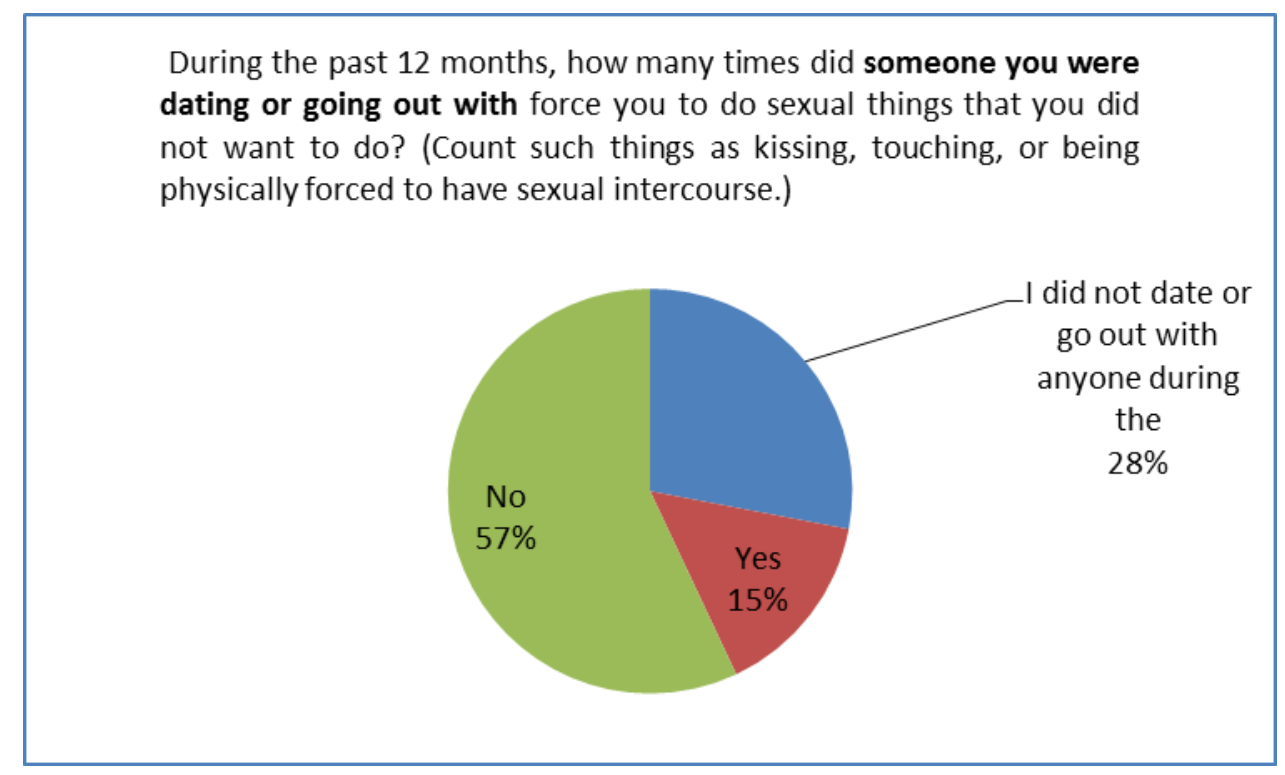

Figure 5: The presence of sexual violence in relationship at the students

Only $15 \%$ of students refer that are forced to do something that they did not want to do (kiss, touch or are physically forced to have sexual intercourse). 


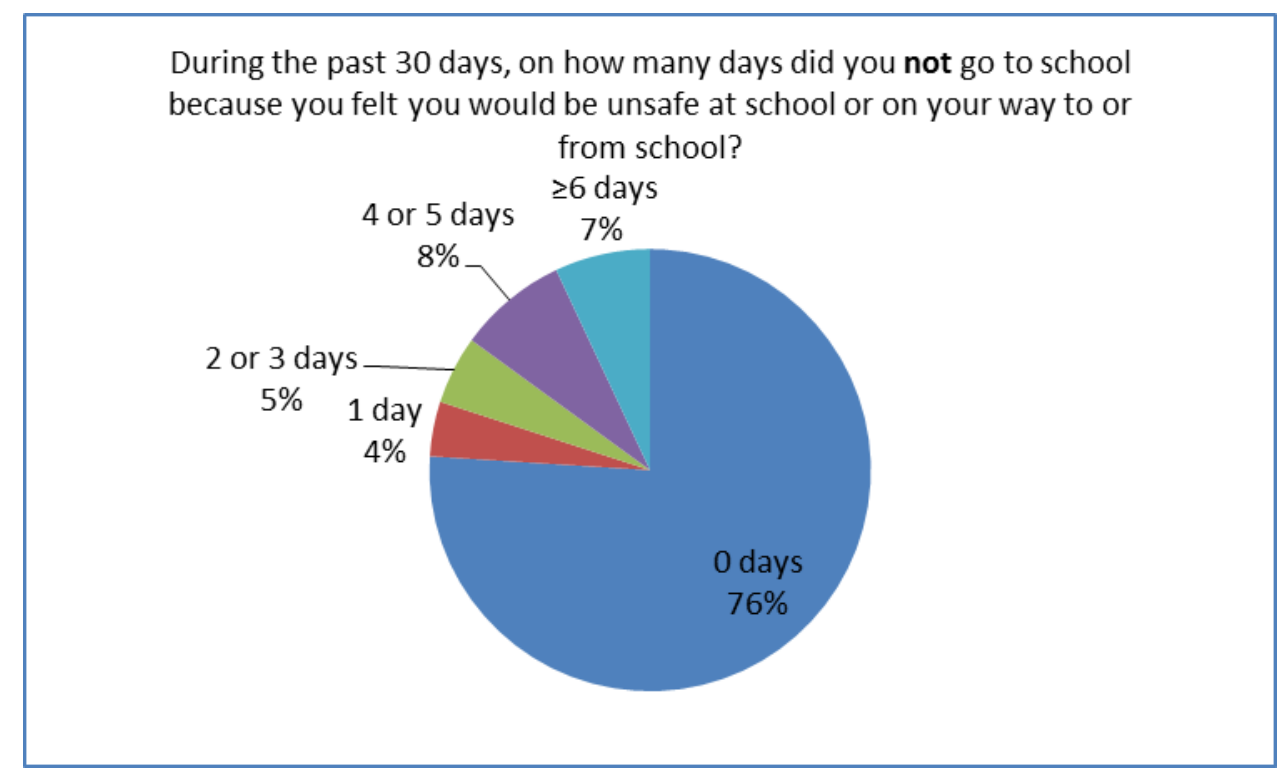

Figure 6: Absences in school due to school insecurity

$24 \%$ didn't participate to school for at least one day during last month because they felt unsafe at school or on the way to or from the school. This reduces students' performance during the learning process.

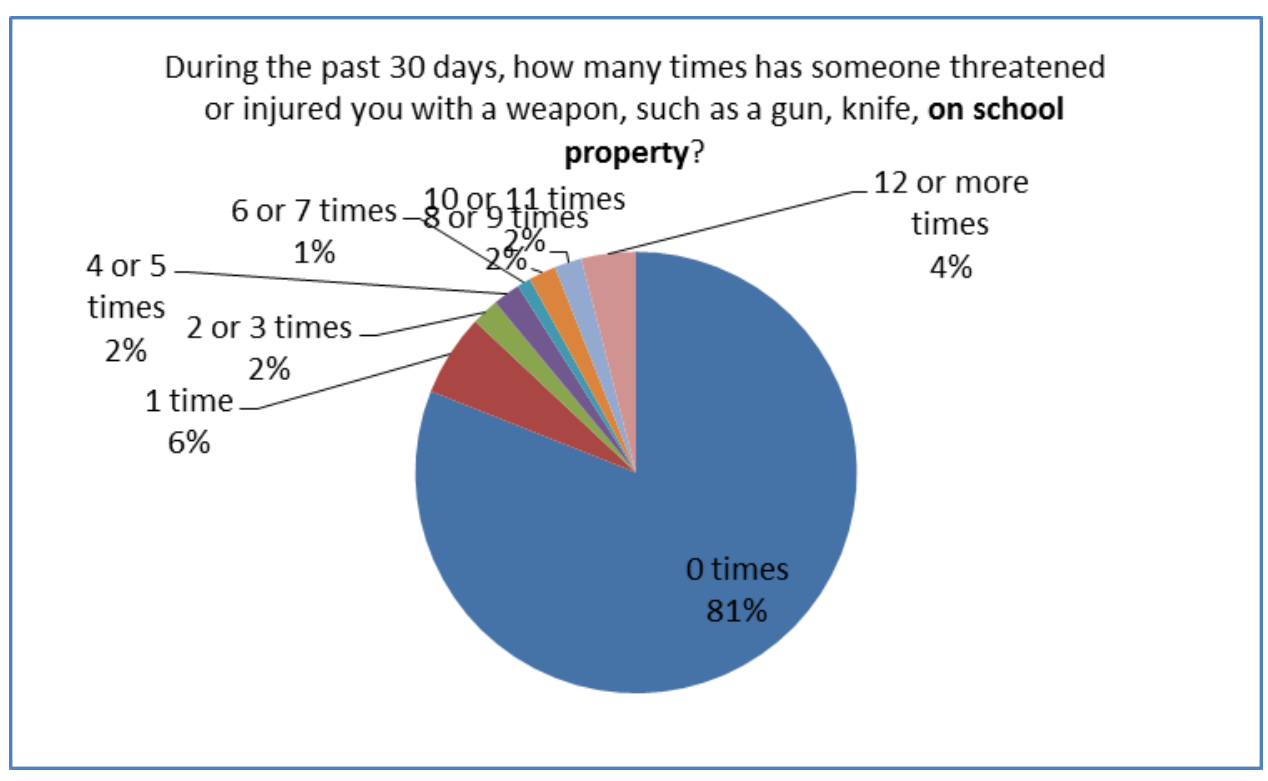

Figure 7: The presence of threats among students with weapons 
$19 \%$ of students refer that someone threatened or injured them at least once during last month with a weapon, such as a gun or a knife This event has occured at the school area or the surrounding environment.

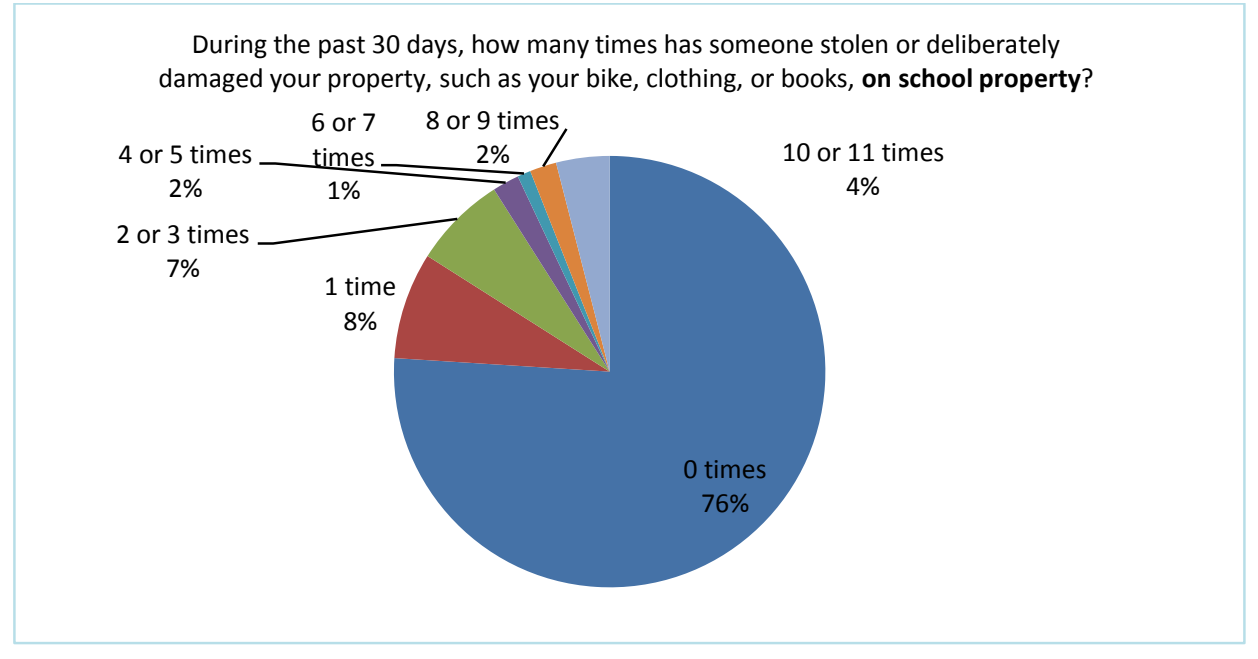

Figure 8: The level of damage of student's property

$24 \%$ of students refer that someone stole or deliberately damaged their property, such as their bikes, clothings, or books, while they were at school area or its surroundings.

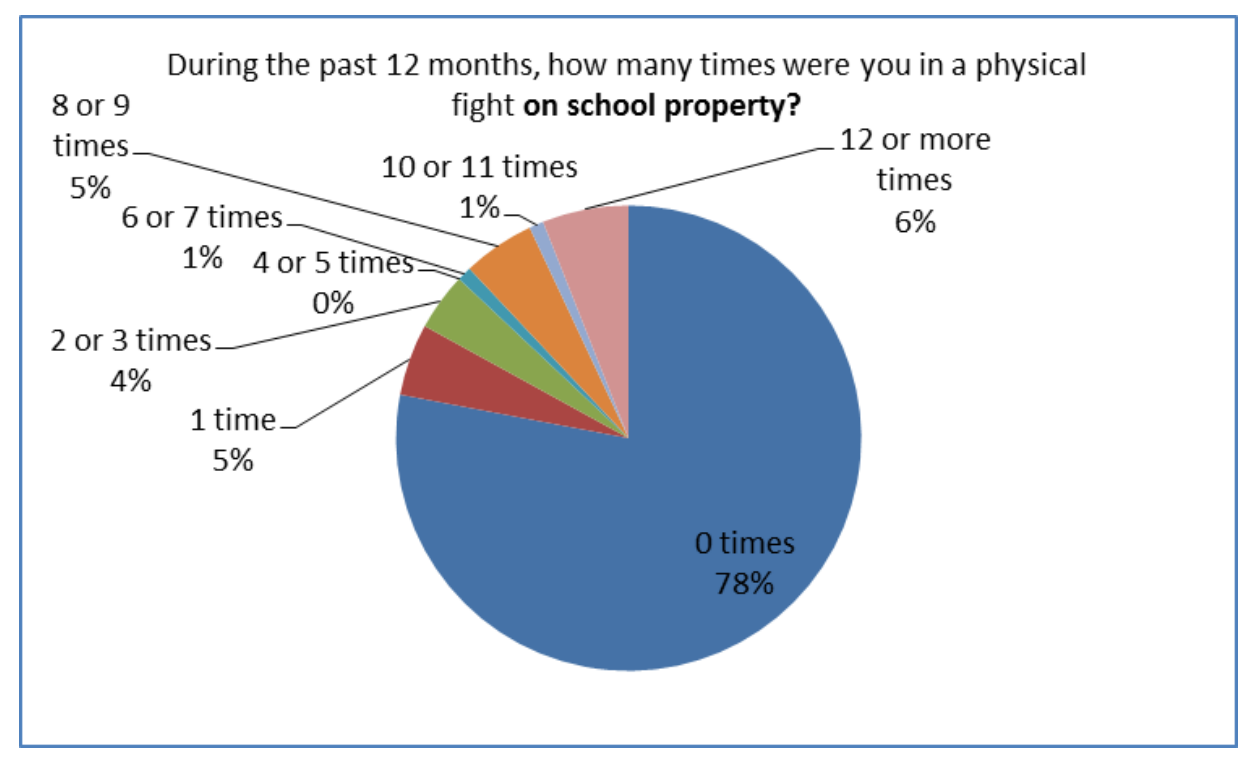

Figure 9: The level of physical violence 
As we can observe at the figure $9 ; 22 \%$

fight at school at least once.

of cases were involved in a physical

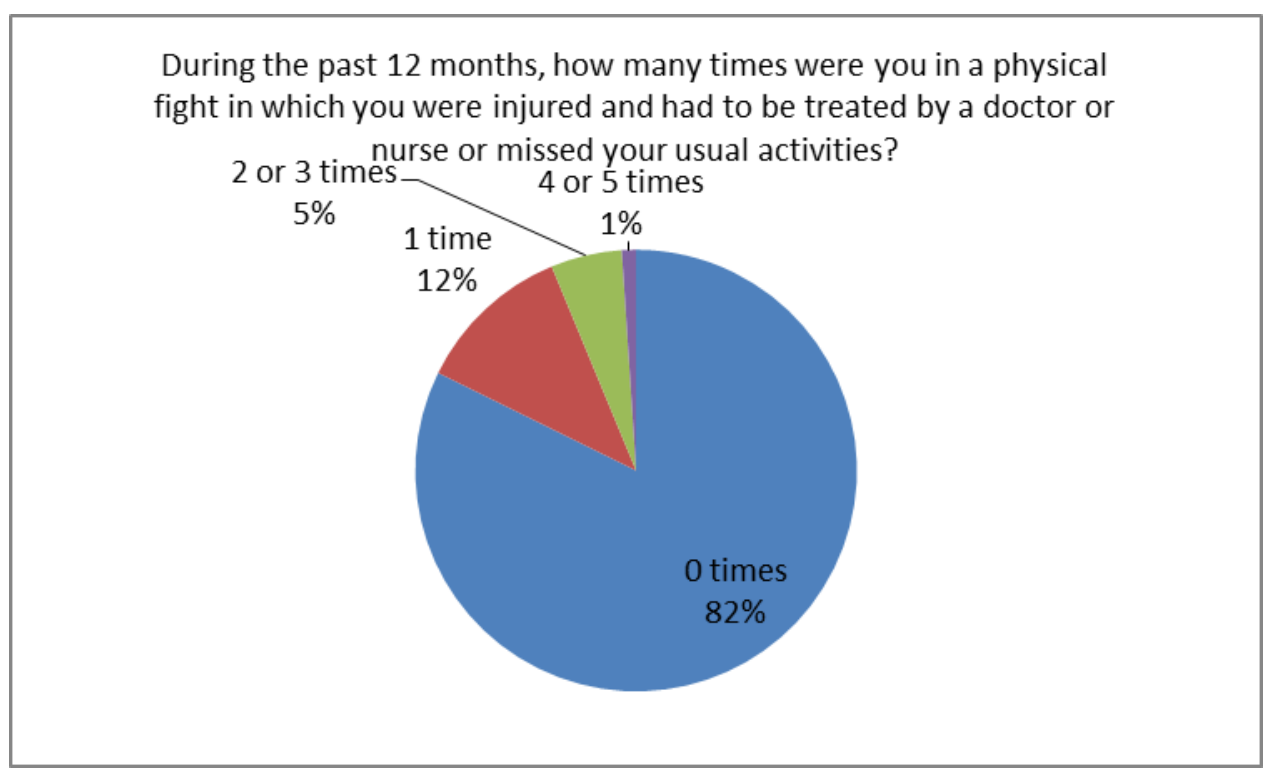

Figure 10: The level of injuies from physical violence

$18 \%$ were involved in a physical fight in which they were injured and have had to be treated by a doctor or nurse or missed their usual activities at least once.

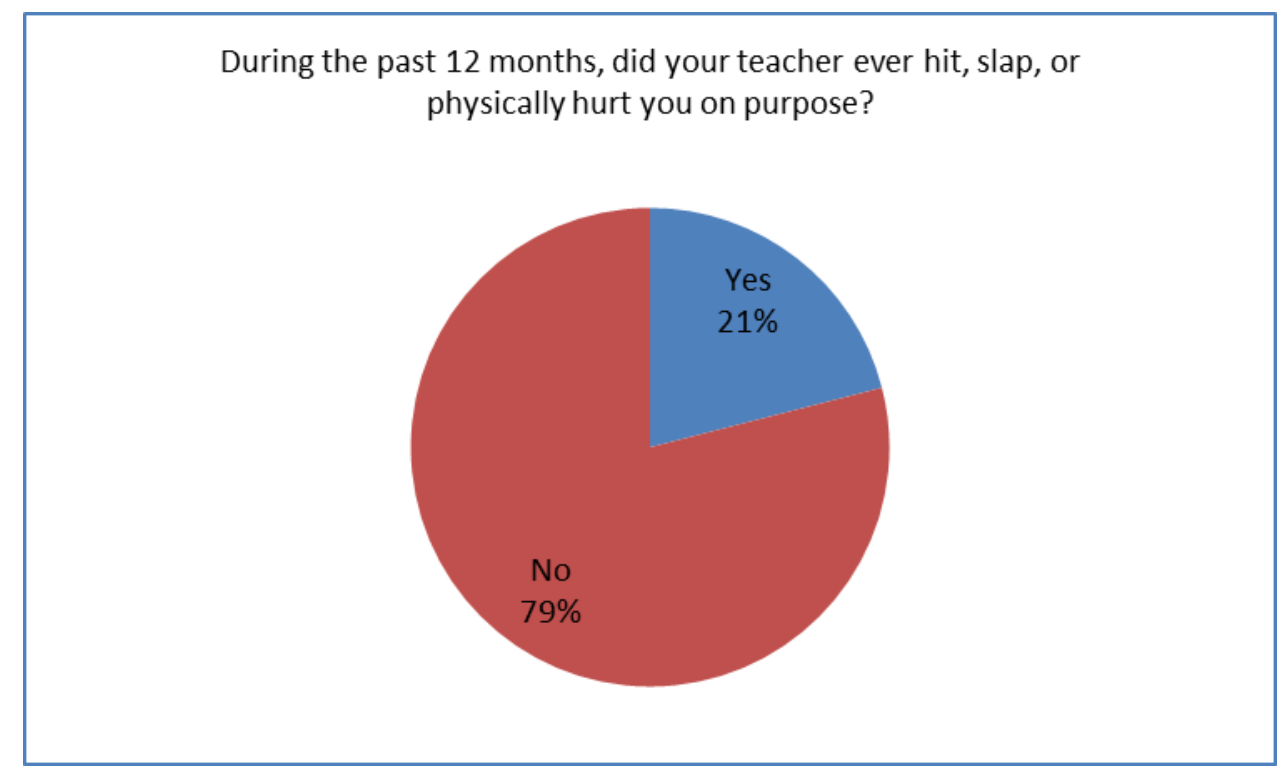

Figure 12: The level of violence at the students from teachers 
$21 \%$ refer that they were violated at

teachers. school (hit, slap, or physically hurt) by

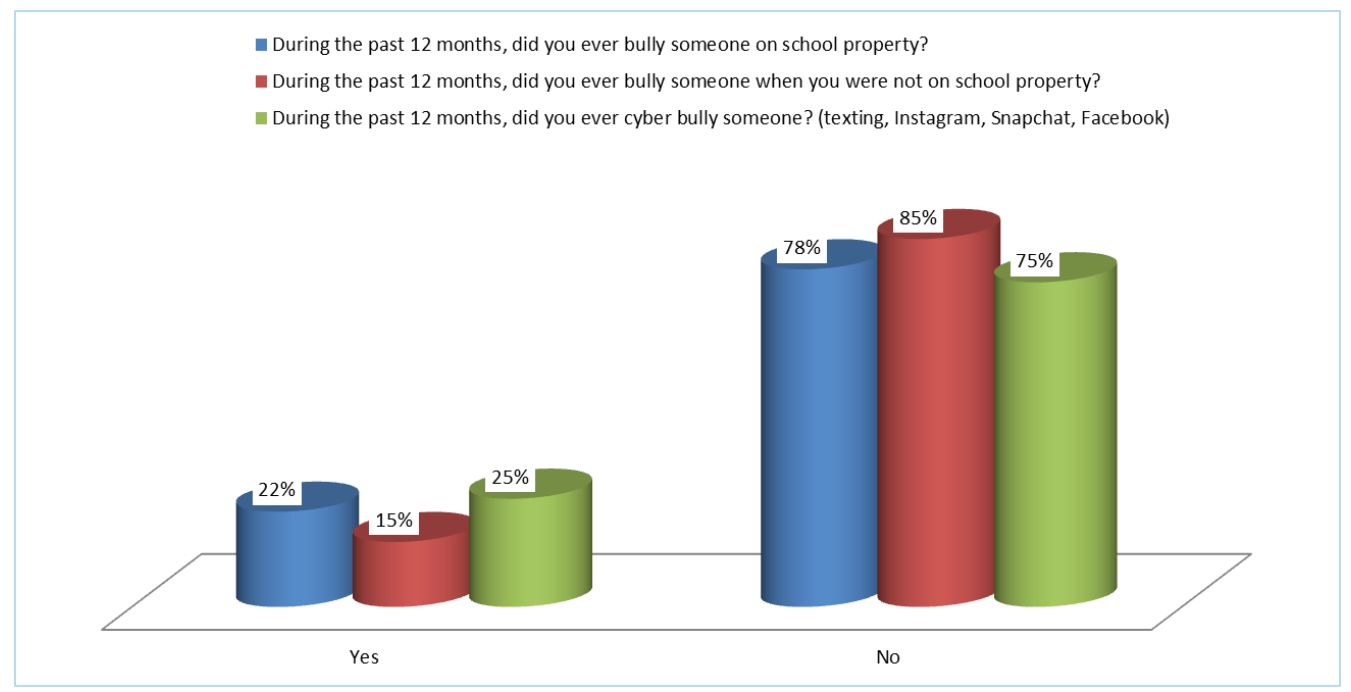

Fig. 12. The place and type of bullying

More than $15 \%$ of students bully cyber bully someone at school or out of it. In $56 \%$ of cases the violence was only psychological, $22 \%$ psychological and physical, $22 \%$ was only physical. $67 \%$ of cases were male students practicing violence.
In $20 \%$ of cases the students intervene when they were present in the physical fight, $22 \%$ are spectators and the others are indiferent. This indiferentism is a big problem for the society and the future of our popullation.

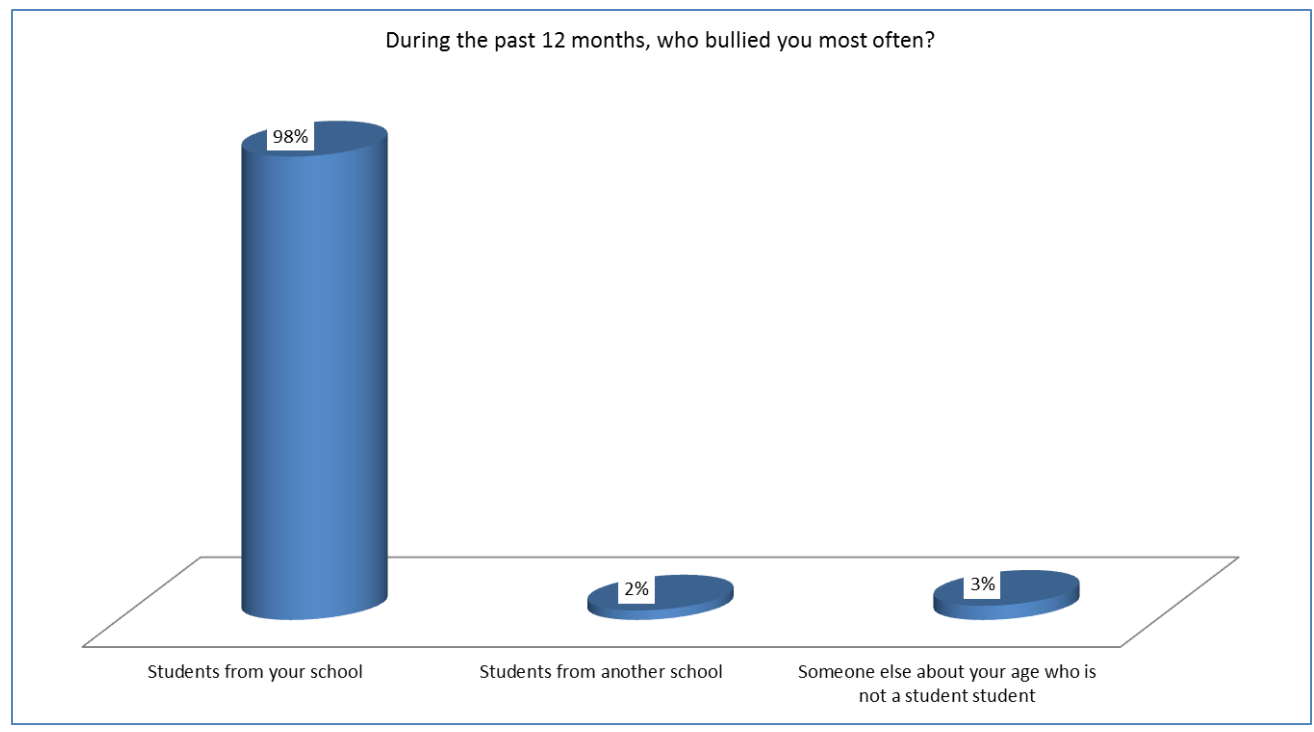


Figure 13: The situation of bullying

$25 \%$ of the bullied students refer that in

$98 \%$ cases the bullism comes from

students of their own school.

During this school year, were you taught in any of your classes what to do if someone is trying to force you to have sexual intercourse?

During this school year, were you taught in any of your classes how to avoid physical fights and violence?

During this school year, were you taught in any of your classes how to avoid being bullied?

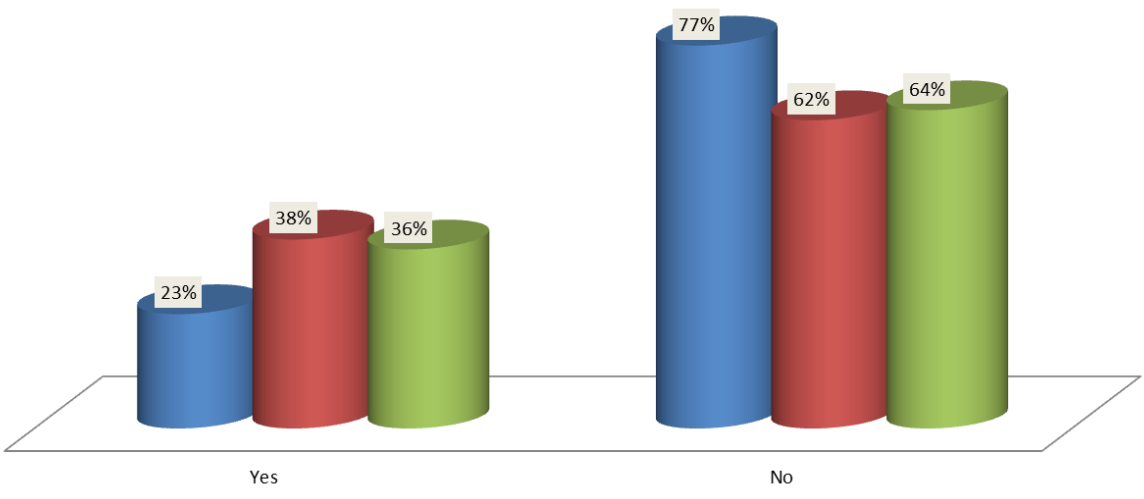

Figure 14: The level of knowledgeand information at students about the protection and prevention from violence

Only $23 \%$ refer that they have discussed and are informed at their classes about the ways to avoid bullism, to avoid

\section{Conclusions}

We conclude that violence exists at the school that was subject of our study. The students are exposed to violence both at home and at school (students, teachers and parents). They are bullied most often from students of their own school. The students that are involved in this situations carry guns or knives at school or outside it . A small group refers that they forced to do something that they did not want to (kiss, touch or are physically forced to have sexual intercourse). physical fights and violence and what to do if someone is trying to force them to have sexual intercourse.

The cases when students missed their classes because of violence fear are not rare. Students report to have missed the schooldays a least once because they felt unsafe at school or on the way to school since someone would threaten or injure them.

They also refer that someone has stolen or deliberately damaged their property, such as bikes, clothings, or books, while at school and its surroundings.

More than 22\% were involved in a physical fight at school at least once, at which they were injured and had to be treated by a doctor or nurse or they 
missed their usual activities at least once.

\section{References}

Violence was only psychological in more than half of cases, $67 \%$ of cases were male students practicing violence. Students were indiferent in more than half of cases when they were present in a physical fight.

The level of knowledge and information at their classes about the how to avoid being bullied, to avoid physical fights and violence and what to do if someone is trying to force them to have sexual intercourse is low.

\section{Recommendations}

- In order to prevent violence between students, the drafting of teaching strategies should be done by increasing their academic performance.

- Curriculums should provide strategies to prevent violence.

- We recommend positive school culture and radical programs against violence at school.

- We need to promote proper behavior and create a fair discipline system by increasing students' confidence in the rules and values of law.

- The training of mothers and teachers as the best mediator is needed in order to resolve the possible conflicts.

- It is obligatory to build strategies that deal with classroom relationship between teachers and their students in order to prevent violation by teachers.

1. https://www.paho.org/hq/inde x.php?option=com_docman\&tas k=doc_view\&gid=44259\&Itemid $=270 \& l a n g=\mathrm{en}$.

2. Lockwood, P., \&Kunda, Z. (1997). Superstars and me: Predicting the impact of role models on the self. Journal of Personality and Social Psychology, 73(1), 91103.http:/ / dx.doi.org/10.1037/0 022-3514.73.1.91

3. Anne C. Grunseit; Don Weatherburn ; Neil Donnelly 2005. "School Violence and Its Antecedents: Interviews with High School Students". NCJ $209450 . \quad$ Pg.104. https://www.ncjrs.gov/App/Pu blications/abstract.aspx?ID $=2094$ $\underline{50}$

4. Pulido, R.; Martin Seoane, G.; Diaz Aguado, M. J. 2010. School Violence Roles and Sociometric Status among Spanish Students. US-China Education Review v7 n1 p51-61 Jan 2010

5. Nickerson AB, Martens MP. School violence: Associations with control, security/enforcement, educational/therapeutic approaches, and demographic factors. SchPsychol Rev. 2008;37:228-243. 
6. Greene MB. Reducing violence and aggression in schools. Trauma Violence Abuse. 2005;6:236-253.

7. Lindstrom Johnson S. Improving the school environment to reduce school violence: A review of the literature. J Sch Health. 2009;10:451-465.

8. Greene MB. Reducing school violence: School based curricular programs and school climate. The Prevention Researcher. 2008;15:12-16. 